\title{
O QUE A OBRA DE PAULO FREIRE NOS CONVIDA A PENSAR?
}

\author{
WHAT DOES PAULO FREIRE'S WORK INVITES US TO \\ THINK?
}

\section{¿QUÉ NOS INVITA A REFLEXIONAR LA OBRA DE PAULO FREIRE?}

\author{
Maria Elisa S Borges ${ }^{1}$ \\ http://orcid.org/0000-0003-4227-2322 \\ ${ }^{1}$ Universidade Federal Fluminense/Volta Redonda, Rio de Janeiro- Brasil. E-mail: \\ mariaelisaborges@id.uff.br
}

\section{Resumo}

Este artigo tem por objetivo dar visibilidade à epistemologia criada por Paulo Freire. Para além de seu método de alfabetização de adultos, Freire criou uma filosofia do conhecimento que, após muitos anos, continua a gerar novas pesquisas em vários campos do conhecimento, sempre convidando à reinvenção. As considerações sobre a atividade de pesquisa em ciências sociais de Becker justificam essas reinvenções. Como exemplo, o artigo apresenta a ergologia, uma abordagem pluridisciplinar criada pelo filósofo francês Yves Schwartz como um projeto de conhecer e, principalmente, intervir em situações de trabalho para transformá-las. Uma das inspirações de Schwartz ao criar a ergologia foi a epistemologia de Paulo Freire.

Palavras-chave: Paulo Freire. Epistemologia. Ergologia.

\begin{abstract}
This article aims to give visibility to the epistemology created by Paulo Freire. Beyond his adult literacy method, Freire created a philosophy of knowledge that, after many years, continues to generate new research in various fields of knowledge, always inviting a reinvention. The considerations of Becker about social science research activities justify these reinventions. For example, the article presents Ergology, a multidisciplinary approach created by the French philosopher Yves Schwartz as a project to know and, mainly, to intervene in work situations to transform them. One of Schwartz's inspirations when creating Ergology was Paulo Freire's epistemology.
\end{abstract}

Keywords: Paulo Freire. Epistemology. Ergology. 


\section{Resumen}

Este artículo tiene como objetivo dar visibilidad a la epistemología creada por Paulo Freire. Además de su método de alfabetización de adultos, Freire creó una filosofía del conocimiento que, después de muchos años, sigue generando nuevas investigaciones en diversos campos del conocimiento, invitando siempre a la reinvención. Las consideraciones de la actividad investigadora en ciencias sociales de Becker justifican estas reinvenciones. Como ejemplo, el artículo presenta la ergología, un enfoque multidisciplinar creado por el filósofo francés Yves Schwartz como un proyecto para conocer $y$, principalmente, intervenir en situaciones laborales para transformarlas. Una de las inspiraciones de Schwartz al crear la ergología fue la epistemología de Paulo Freire.

Palabras clave: Paulo Freire. Epistemología. Ergología.

\section{Introdução}

Em 2021 comemora-se o centenário de nascimento de Paulo Freire e várias homenagens vêm sendo feitas em todo o mundo. Mais do que nunca, é importante afirmar não apenas a importância de sua obra, mas também sua permanência ao longo dos anos.

Apesar de ser conhecido mundialmente por seu método de alfabetização de adultos, Freire criou muito mais do que isso. Na verdade, reconhecê-lo apenas a partir de seu método de alfabetização é reduzir, é apequenar sua obra, o que pode ser compreendido a sob duas perspectivas: ou por falta de conhecimento de sua produção ou por uma tentativa deliberada de encobri-la.

Nesse sentido, este artigo tem por objetivo evidenciar o fato de que Freire criou uma epistemologia, uma filosofia do conhecimento, uma maneira de pensar e de ver o mundo. E a atualidade de sua obra reside exatamente nisso, no fato de continuar gerando novas pesquisas através dos tempos, em vários campos do conhecimento, sempre nos convidando a reinventá-la. Diversos trabalhos nos campos da educação, psicologia, arquitetura, filosofia, teatro, poesia, entre outros, têm se inspirado na epistemologia freiriana.

$\mathrm{O}$ artigo começa refletindo sobre algumas ideias freirianas importantes para compreender a obra de Paulo Freire como uma filosofia do conhecimento como a vocação para humanização, a relação opressor-oprimido e a práxis libertadora, que são essenciais para essa compreensão. 
Em seguida, faz algumas considerações sobre a atividade de pesquisa a partir das reflexões de Becker (1999), no sentido de argumentar sobre as várias maneiras de fazer pesquisa em Ciências Sociais e como a obra de Freire nos convida a essa recriação.

Finalmente, o artigo apresenta a ergologia, abordagem pluridisciplinar que tem como objeto de estudo o trabalho humano, inspirada na obra de Paulo Freire. A ergologia é um projeto de conhecer e, principalmente, intervir em situações de trabalho para transformá-las e transita pelo mesmo campo epistemológico freiriano. É apenas um dos exemplos de como a obra de Freire continua viva e pulsante para muito além do campo da alfabetização de adultos.

\section{Alguns conceitos freirianos}

Alguns conceitos da obra de Freire nos ajudam a compreender a filosofia do conhecimento criada por ele, conceitos que podem parecer fáceis e óbvios em uma leitura rápida, mas que necessitam de aprofundamento para serem adequadamente compreendidos.

\subsection{A vocação para a humanização}

Freire (1970) começou, como todos os filósofos, a fazer a pergunta essencial: o que é um ser humano? Quem somos? O que estamos fazendo aqui neste mundo? Ou, como diria Caetano Veloso (1982), em sua belíssima canção Cajuína: "Existirmos, a que será que se destina?".

Freire ensina que os seres humanos têm a vocação para a humanização, para o ser mais. Essa vocação se expressa por um ser humano que está em permanente procura, buscando conhecer a si mesmo e ao mundo, buscando se desenvolver intelectualmente, moralmente e afetivamente.

A natureza humana nunca é determinada, é sempre inacabada e inconclusa, um eterno vir a ser. O ser humano não é algo pronto e acabado, está sempre recomeçando, criando-se e recriando-se; em cada momento da vida, ainda não é tudo que pode vir a ser. Há sempre mais a saber, mais a amar, mais a fazer, mais a contemplar, mais a sonhar, mais a conhecer. O humano jamais acaba de se tornar humano. 
E, por serem racionais, seres de pensamento, os humanos sabem que são inacabados e inconclusos. Outras espécies animais também são inconclusas, mas não sabem disso. Os humanos têm consciência disso e é por causa dessa consciência do inacabamento e das infinitas possibilidades que isso traz que se torna possível aprender; é isso que possibilita a educação.

É essa condição de inacabamento que pode trazer esperanças em relação ao futuro, pois os humanos sempre podem se tornar mais humanos. E a História não está pronta, ela se faz cotidianamente.

\subsection{A relação opressor-oprimido}

Para Freire (1970), essa vocação ontológica de ser mais é negada tanto aos oprimidos quanto aos opressores pela realidade histórica de opressão. E somente a práxis libertadora do oprimido é capaz de restaurar a humanidade em ambos.

Trata-se de uma ideia central na obra de Freire essencial para a compreensão de sua obra. Se essa ideia não é compreendida corretamente, corre-se o risco de atribuir-lhe um caráter maniqueísta - uma luta entre o bem e o mal.

Alguns questionam essa afirmação ao supor que apenas os oprimidos têm sua humanidade negada na medida em que as próprias condições de uma vida digna lhe são negadas, suas vozes são silenciadas e sua própria atuação no mundo como sujeitos é desqualificada. Já em relação aos opressores, um olhar rápido e equivocado diria que sua humanidade não é negada porque suas vozes são ouvidas, sua atuação no mundo é considerada importante e possuem direitos e privilégios.

Mas Freire é muito claro quanto a isso:

A desumanização não se verifica apenas nos que têm sua humanidade roubada, mas também, ainda que de forma diferente, nos que a roubam (1970, p. 30).

E continua...

\footnotetext{
...o opressor se desumaniza ao desumanizar o oprimido. Não importa que coma bem, que vista bem, que durma bem. Não seria possível desumanizar sem desumanizar-se, tal a radicalidade social da vocação. Não sou se você não é, não sou, sobretudo, se proíbo você de ser (1970, p. 30).
} 
Tanto opressores quanto oprimidos se encontram impedidos de serem plenamente humanos porque é a própria relação de opressão que impede a ambos de realizarem a vocação histórica de ser mais.

O opressor se desumaniza no ato da opressão; ao oprimir, ele se desumaniza porque proíbe o outro de ser, ele trai a sua vocação ontológica de ser mais, ele abandona essa vocação.

O oprimido é desumanizado pela realidade objetiva da opressão a que ele é submetido ao não ter acesso a uma vida digna, ao ter sua voz silenciada e ao ser, muitas vezes, tratado como um não-sujeito.

Não é só por essa via, no entanto, que ele se desumaniza, mas também pela internalização que faz da imagem do opressor, o que o torna um ser duplo. E é aqui que a questão fica mais complexa, pois estamos diante de uma contradição: o oprimido é hospedeiro do opressor, ou seja, o oprimido possui um opressor dentro de si e isso mantém a relação de opressão.

Essa é uma contradição, a identificação do oprimido com o seu contrário. Em um primeiro momento, antes de qualquer reflexão, a única saída que o oprimido vislumbra para deixar de ser oprimido seria a de se tornar opressor, tornar-se o seu contrário, deixar de ser escravo para ser feitor, deixar de ser camponês para se tornar um capataz, deixar de ser empregado para ser patrão.

Como compreender isso? Freire nos ensina: o comportamento dos oprimidos é prescrito pela relação de opressão, os oprimidos têm no opressor o seu testemunho de humanidade. O seu ideal de humanidade é forjado nessa contradição em que sempre estiveram presentes, os oprimidos assumem uma postura de aderência ao opressor e seu conhecimento como oprimidos se encontra prejudicado porque estão imersos em uma realidade opressora.

Os oprimidos, ao procurarem recuperar sua humanidade, não podem ter como ideal serem opressores dos opressores, mas restauradores da humanidade em ambos. E isso só é possível a partir da práxis libertadora, outra ideia fundamental na obra de Paulo Freire. 


\subsection{A práxis libertadora}

Para aprofundar essa contradição do oprimido, Freire busca a ajuda de Hegel (1807), que fez uma construção teórica, que ele chamou de "dialética do senhor e do escravo", para explicar como se forma a nossa consciência.

É importante dizer que Hegel não está falando da escravatura como fenômeno histórico, mas usando uma imagem, uma alegoria para explicar como se forma a consciência.

Simplificando essa construção teórica, ressaltando apenas os elementos que vão nos ajudar a compreender a relação opressor/oprimido, vemos que a formação da consciência, segundo Hegel, começa quando dois desejos humanos são confrontados, ou seja, quando duas pessoas desejam a mesma coisa. Nessa disputa pelo mesmo objeto de desejo, um vai ser o vencedor - o senhor - e outro será o perdedor - o escravo.

Para Hegel (1807), a consciência só pode ser formada por meio do reconhecimento do outro. Assim, o escravo vai reconhecer o outro como senhor e a si mesmo como escravo, ou seja, como inferior ao seu amo. Ele se torna uma "coisa" para o senhor, cria uma "consciência para o outro", ou seja, uma "consciência servill".

O senhor, que é servido pelo escravo, desenvolve, a princípio, uma "consciência para si", reconhecendo-se e sendo reconhecido como alguém superior ao escravo.

A partir daí, nesse caminho de formação da consciência, uma contradição se coloca: o escravo, ao trabalhar para suprir as necessidades do senhor, compreende que, mediante seu trabalho, pode transformar o mundo. Ele entra em contato com as matérias-primas do mundo e as transforma em seu processo de trabalho. E, embora o resultado de seu trabalho não seja destinado ao seu consumo (assim como o operário que produz tijolos, mas não tem uma casa para morar), ele entende que pode transformar o mundo a partir do trabalho.

Mesmo se sentindo inferior e impotente diante do senhor, o escravo não perde a noção de que o mundo pode ser transformado. Por estar em contato com o mundo, onde ele pode intervir e transformar, ele começa a desenvolver uma "consciência para si". A partir do entendimento de que seu trabalho transforma o mundo, deixa de se reconhecer como "coisa" e não mais se reconhece como inferior ao senhor, formando também uma "consciência para si". 
O senhor, por sua vez, afasta-se do mundo na medida em que não trabalha e deixa de saber como transformar o mundo; passa a depender completamente do escravo para sobreviver no mundo do qual se afastou, E, por isso, desenvolve uma "consciência para o outro", ou uma consciência servil.

O senhor só é senhor porque tem escravos; se deixa de ter escravos, deixa de ser senhor; também o escravo só é escravo se tem um senhor. Ou seja, os dois estão aprisionados em uma relação de acorrentamento. É exatamente essa imagem que Hegel apresenta: um senhor e um escravo atados por uma corrente da qual só podem se libertar juntos, sendo que a vantagem do escravo é que ele percebe que tem a escolha de se libertar a partir da reflexão sobre a sua condição de escravo.

Freire (1970) se inspira na imagem do senhor e do escravo acorrentados, mas se distancia de Hegel no sentido de que entende que apenas a reflexão não é suficiente; é preciso ir além. A dialética, para Freire, precisa ser mais do que um processo teórico de reflexão, é necessário implicar ação, prática. Ele afirma que essa relação de senhor e escravo não é apenas uma alegoria, um modo de explicar o surgimento da consciência, mas faz parte de uma realidade concreta dos seres humanos desumanizados.

\footnotetext{
Não basta saberem-se numa relação dialética com o opressor - seu contrário antagônico - descobrindo, por exemplo, que sem eles o opressor não existiria (Hegel), para estarem de fato libertados. É preciso, enfatizemos, que se entreguem à práxis libertadora (p. 36)
}

E aqui surge um conceito fundamental na obra de Freire: a práxis libertadora, definida por ele como um processo de reflexão e ação contínuo e permanente de homens e mulheres sobre o mundo para transformá-lo.

Sem a práxis libertadora, é impossível a superação da contradição opressoroprimido. Reflexão e ação precisam estar juntas numa espiral crescente e permanente.

Diferentemente de Hegel, que acreditava que a consciência se forma apenas pela reflexão, para Freire, a consciência só se torna plena na práxis: na reflexão e na ação, juntas e indissociáveis. Não basta refletir, é preciso agir no mundo para transformá-lo. E essa é uma tarefa de homens e mulheres como seres históricos em seu processo de ser mais. 


\title{
3 Considerações sobre a atividade de pesquisa
}

Coerente com a epistemologia freiriana, este artigo defende a ideia de que os métodos de pesquisa devem ser sempre reinventados e partir da situação real de pesquisa.

Fazer pesquisa, segundo Becker (1999), deve ser uma prática artesanal, sendo necessário que haja criatividade na proposta metodológica. $\mathrm{O}$ pesquisador deve se sentir convocado a inventar métodos que sejam capazes de elucidar os problemas de suas pesquisas. Deve se sentir livre para desenvolver ideias mais relevantes aos fenômenos que ele próprio pesquisa, levando em consideração as contribuições dos que o precederam, mas evitando a exigência de utilizar apenas o que foi inventado por outros. $\mathrm{O}$ pesquisador deve construir métodos dialogando com seu meio, levando em conta o que ele vive em seu próprio trabalho de pesquisa.

\begin{abstract}
Prefiro um modelo artesanal de ciência, no qual cada trabalhador produz as teorias e métodos necessários para o trabalho que está sendo feito. É como mandar construir uma casa para si. Embora existam princípios gerais de construção, não há dois lugares iguais, não há dois arquitetos que trabalhem da mesma maneira e não há dois proprietários com as mesmas necessidades. Assim, as soluções para os problemas de construção têm sempre que ser improvisadas. Estas decisões não podem ignorar princípios gerais importantes, mas os princípios gerais em si não podem resolver os problemas desta construção. Para fazê-lo, temos que adaptar os princípios gerais à situação específica que temos em mãos. (p. 12)
\end{abstract}

Pesquisas qualitativas têm menos probabilidade do que as quantitativas de serem explícitas sobre seus métodos. As situações de pesquisa qualitativa exigem, sempre, a improvisação e uma ligação estreita com a situação a ser pesquisada.

Para fazê-lo, temos que adaptar os princípios gerais à situação específica que temos em mãos.

Os princípios gerais encontrados em livros e artigos sobre metodologia são uma ajuda, mas, sendo genéricos, não levam em consideração as variações locais e peculiaridades que tornam este ambiente e este problema aquilo que são de modo único. (p.1 3)

Toda pesquisa tem o propósito de resolver um problema específico que, em seus aspectos mais relevantes, não é parecido com qualquer outro problema, e a sua 
resolução deve ser feita em um ambiente específico e diferente de todos os que existiram antes. Os princípios gerais encontrados em livros e artigos sobre metodologia são uma ajuda, mas, sendo genéricos, não levam em consideração as variações locais e peculiaridades do ambiente e do problema específico que se quer abordar. Assim, o pesquisador em ciências sociais não somente pode como deve improvisar as soluções que funcionam e resolvem os problemas que ele espera elucidar.

Becker (1999) considera a metodologia uma especialidade proselitizante por causa dessa propensão muito forte dos metodólogos a apregoar uma "maneira certa" de fazer as coisas devido ao seu desejo de converter todos os estilos de trabalho a um único estilo "apropriado" e também devido à sua relativa intolerância com o "erro".

Os problemas inerentes às pesquisas refletem as peculiaridades do grupo social que estudamos. Ao resolvê-los, aprende-se simultaneamente alguma coisa sobre a estrutura social em observação e também algo sobre os métodos que são usados. Quando os métodos "habituais" são adaptados a um ambiente de pesquisa específico, é porque alguma coisa em relação ao ambiente está organizada de maneira diferente do que era esperado.

Essa maneira de trabalhar criando métodos apropriados a cada situação tem suas próprias vantagens alternativas. Em vez de tentar colocar as observações sobre o mundo numa camisa de força de ideias desenvolvidas em outro lugar, em outro tempo, para explicar fenômenos peculiares a este tempo e a este lugar, os cientistas sociais podem desenvolver as ideias mais relevantes para os fenômenos que eles próprios desvelaram.

Dessa forma criativa, Freire tem inspirado muitos campos de conhecimento a reinventá-lo, atualizando os problemas de pesquisa no tempo e no espaço.

Um dos exemplos dessas reinvenções pode ser conhecido a partir da ergologia, abordagem criada por Yves Schwartz sob inspiração de Freire.

\section{Ergologia - inspiração freiriana}

A ergologia é uma abordagem pluridisciplinar criada pelo filósofo francês Yves Schwartz (2000) como um projeto de conhecer e, principalmente, intervir nas situações de trabalho para transformá-las. Uma das inspirações de Schwartz ao criar a ergologia foi a epistemologia de Paulo Freire. 
A concepção de vida e de educação de Freire e a ergologia partilham do mesmo campo ético epistemológico, um campo que se apresenta como alternativa à tradição clássica cartesiana que afirma que apenas o intelecto e a razão podem ter acesso à verdade; que alega que só a razão conduz ao verdadeiro saber; que uns devem pensar e outros devem apenas seguir e aprender a fazer. Uma lógica cartesiana que afirma que o trabalho é um processo do corpo e a educação e o pensamento são processos da mente.

De forma bem diferenciada, o campo ético epistemológico compartilhado pela filosofia de Freire e a ergologia de Schwartz afirma que o conhecimento não está fora do humano, à espera de ser descoberto. O conhecimento é construído no cotidiano por homens e mulheres, com seus saberes diferentes e não hierarquizáveis.

Não se trata de negar o conhecimento já construído por homens e mulheres ao longo da história, mas, sim, de considerar que ele é sempre parcial e incompleto, está sempre em estado de inacabamento e inconclusão.

A ergologia e a filosofia freiriana dialogam muito bem e alguns dos conceitos de Freire são fundamentais para a compreensão desse diálogo.

Como vimos, Freire considera que a educação tem como tarefa principal a humanização, a vocação humana para "ser mais". Essa busca desse "ser mais" revela uma natureza humana inacabada, um vir a ser. Nesse processo de "se fazer", as pessoas criam cultura, modificam o mundo, inventam novos modos de ser e de interagir com as outras. Os processos de aprendizagem são processos de criação e a motivação para criar nasce da consciência da inconclusão e do inacabamento.

No mesmo sentido, a ergologia parte da ideia do antropólogo Leroi-Gourhan (1943) de que a espécie humana é industriosa. Ao falar em caráter "industrioso" da espécie humana, Schwartz procura identificar a característica de permanente criação na atividade de trabalho e determinar o que é o trabalho a partir da definição de atividade humana.

Mas o que é atividade? Para compreendê-la, a ergologia parte da distinção entre trabalho prescrito e trabalho real apontada pela ergonomia da atividade.

Em uma situação de trabalho, não há como se ater ao prescrito, àquilo que é determinado antes da realização do próprio trabalho. O trabalho efetivamente realizado nunca é só prescrição e fiel execução de procedimentos, pois envolve sempre as “infidelidades do meio", como nos ensinou Canguilhem (1990). 
O trabalho real convoca sempre a atividade humana para dar conta dele. Atividade que é a mobilização física, psíquica, cognitiva, motora, fisiológica, afetiva, que todo humano coloca em seu trabalho para que ele possa realmente acontecer. Ou seja, atividade de trabalho é tudo aquilo que se faz para dar conta do que precisa ser feito.

Schwartz (2003) afirma que as "infidelidades do meio" se expressam como um "uso de si", e não como mera execução. O termo "execução", tão próprio de uma abordagem taylorista-fordista, supõe, equivocadamente, que o trabalhador apenas siga procedimentos e diretrizes, mas, para que o trabalho seja realizado, é preciso que haja um humano avaliando, fazendo ajustes, escolhas, revisões, renormatizando o tempo todo. O trabalhador faz muito mais do que executar, ele faz "uso de si" ao trabalhar, porque o trabalhar exige toda essa mobilização do sujeito: suas habilidades cognitivas e de afeto, sua história singular etc. Reduzir a atividade de trabalho à mera execução é acreditar que o meio é sempre fiel, que não há acasos nem variabilidades contínuas e constantes, algo que é impensável na ordem da vida.

Pensar em um "uso de si" no lugar da mera execução é fundamental para que possamos sair da armadilha de acreditar que o trabalhador é um humano fundamentalmente passivo, puramente reprodutor, que apenas sofre os impactos dos determinismos históricos, econômicos e sociais. Se essas condições históricas fazem parte das normas que antecedem qualquer trabalho, o trabalho efetivamente realizado nunca é apenas isso, pois o humano, ao praticar um "uso de si", não só varia, mas produz variações, como nos ensinou Canguilhem (1990).

Esse é o ângulo a partir do qual a ergologia aborda o trabalho: do ponto de vista daquele que trabalha, de sua potência e de suas dificuldades. Os processos de aprendizagem no trabalho são de criação, gerados pelo desejo industrioso do humano, movidos por sua inconclusão e inacabamento. Processos realizados por sujeitos da história, como nos ensinou Paulo Freire.

A segunda ideia na qual a ergologia e epistemologia freiriana se aproximam é a de "saberes de experiência feitos". O trabalho real ao qual a ergologia se refere, aquele que vai além das regras e procedimentos, assemelha-se ao que Freire denominou "saberes de experiência feitos", definido por ele como "concepções não científicas (embora atravessadas por conhecimentos científicos) construídas por homens e mulheres sobre si mesmos e sua própria realidade" (Freire, 1970). 
O "saber de experiências feito" é um patrimônio do educando quando ele chega no encontro com o educador; patrimônio construído em sua relação com o mundo e com os outros e que será modificado por esse novo encontro em uma educação dialógica. É também um patrimônio do trabalhador, que já traz todo um saber encarnado no corpo quando chega ao seu local de trabalho, o que vai ser fundamental para fazer o trabalho acontecer. Assim como o educando em sala de aula, o trabalhador é protagonista em sua atividade de trabalho.

Outro ponto em comum na obra de Freire e na ergologia é a dialogicidade. A ergologia, desde o início, compreendeu, sob a inspiração de Freire, que, para desenvolver seus estudos sobre o trabalho, seria necessária a participação das próprias pessoas que trabalham e que possuem a experiência do trabalho.

Nesse sentido, desenvolveu um dispositivo metodológico, denominado “dispositivo dinâmico em três polos", que acontece a partir de debates entre dois polos: os saberes científicos e os saberes da prática dos trabalhadores (os tais "saberes de experiências feitos"). O terceiro polo, que vai servir de mediador entre os dois primeiros, é o polo ético-epistemológico, que inclui os acordos coletivos que devem ser feitos para que o dispositivo funcione. Para Schwartz, é indispensável que, no terceiro polo. haja uma atitude de humildade, que, inspirado em Freire, ele chamou de humildade epistemológica.

Para Freire, o conceito de humildade consiste na luta em favor do respeito, da defesa de direitos e da dignidade enquanto prática ética, sendo uma exigência de todo educando e de todo educador. Humildade não é submissão, não é modéstia ou fraqueza, aproxima-se muito mais da amorosidade, do respeito, da tolerância e da luta por direitos humanos. Essa postura de humildade permite, segundo a ergologia, que haja o respeito ao olhar do outro e à contribuição de cada saber. Permite compreender que nenhum saber vai dar conta da complexidade do real do trabalho, que é necessário o encontro de vários saberes para tentar se aproximar desse real.

Freire afirma que o conhecimento só pode ser construído em conjunto, no "entre”, em comunhão. Construção de conhecimento é sempre coconstrução. 
A potência do dispositivo dinâmico em três polos está exatamente no que é produzido "entre" os saberes - científicos e da experiência. A proposta é de uma produção coletiva de conhecimentos, o que sempre exige, além do domínio de saberes, uma postura de humildade diante do saber do outro.

É preciso haver um verdadeiro diálogo entre saberes, e essa dialogicidade é central no projeto da ergologia. Para Freire, é o diálogo que possibilita nossa existência em sociedade como processo, como realidade inacabada e sempre em transformação. Nas suas palavras: "O diálogo é uma exigência da existência" (1970, p. 104). Trata-se de uma busca incessante por um diálogo entre os parceiros, em que todos possam descobrir novas dimensões e possibilidades de vida num processo de formação mútua e permanente. E o diálogo não pode ocorrer entre um que sabe e outro que não sabe, o diálogo deve ser um encontro amoroso, que se dá entre sujeitos com saberes diferentes, em uma relação de confiança em que um reconhece o saber do outro como legítimo. É nesse encontro que se torna possível criar o novo.

Nos encontros concretos, todo corpo é mobilizado - razão, afetos, cognições, fisiologia. Não há hierarquia entre o saber científico e o saber da experiência. A imersão no mundo do trabalho e a aproximação entre os saberes formalizados e os saberes da prática, sem estabelecer hierarquização, permitem a constituição de espaços de discussão que possibilitam a construção de novos saberes e de soluções para os problemas concretos.

Enfim, tanto a educação quanto o trabalho são caminhos para compreendertransformar a realidade.

\section{Considerações finais}

Freire convida a visitar sua obra e reinventá-la sempre, em diferentes contextos. Este artigo apresentou uma dessas possibilidades no campo da Psicologia do Trabalho. Além dessa, existem diversas outras reinvenções em diferentes campos do conhecimento.

A perspectiva de homens e mulheres que estão sempre em construção, sempre em um processo de vir a ser, em estado de inconclusão e inacabamento e de uma História que está sempre em processo de transformação nos traz esperança. 
Como seres da práxis, os humanos são capazes de compreender a realidade e transformá-la a partir da ação-reflexão: agir no mundo; refletir sobre sua ação; voltar à ação sobre a realidade concreta, em um novo patamar de conhecimento; tudo isso em um movimento contínuo. Esse movimento pode ser visualizado a partir da imagem de uma espiral, sempre ascendente, em permanente ampliação, no qual nunca há retorno ao estágio anterior.

Freire afirma uma esperança crítica que não é pura espera. É uma necessidade ontológica que pode e deve ser aprendida, necessitando da ação para se tornar concretude histórica. Por isso há a necessidade de uma educação da esperança, cabendo aos educadores e educadoras não deixar que a esperança se desvie, caindo na desesperança ou no desespero.

A esperança baseada na concretude, na ação, impede a acomodação à realidade $\mathrm{e}$ também a fuga para o puro idealismo, ambos incapazes de transformar a História.

\footnotetext{
...não entendo a existência humana e a necessária luta para fazê-la melhor sem esperança e sem sonho. A esperança é uma necessidade ontológica; a desesperança, esperança que, perdendo o endereço, se torna distorção da necessidade ontológica. (2003, p. 10)
}

Em um momento tão difícil para mundo, em meio a uma pandemia em que tantas vidas foram perdidas, em que muitos sofreram com o afastamento de pessoas queridas, em que muitos abraços foram interditos, em que muitos planos forma interrompidos ou adiados, torna-se urgente restaurar a esperança, reencontrar seu endereço.

Cada vez mais, a obra de Freire é atual no sentido de apostar na esperança, na boniteza, na possibilidade dos inéditos viáveis. Que nós possamos seguir reinventando Paulo Freire. Que possamos seguir esperançando.

\section{Referências}

BECKER, H. Métodos de pesquisa em Ciências Sociais. São Paulo: Hucitec,1999.

CANGUILHEM, G. O normal e o patológico. Rio de Janeiro: Ed. Forense Universitária, 1990. 
FREIRE, P. Pedagogia do oprimido. São Paulo: Ed. Paz e Terra, 1970.

FREIRE, P. Pedagogia da esperança. São Paulo: Ed. Paz e Terra, 2003.

HEGEL, G.W.F. Fenomenologia do espírito. Petrópolis: Vozes, 1992.

LEROY-GOUHRAN, A. L'Home et la matière. Paris: Albin Michel, 1943.

SCHWARTZ, Y. A comunidade ampliada de pesquisa e o regime de produção de saberes. Revista Trabalho e Educação, n. 7, p. 39-46, 2000.

SCHWARTZ, Y. Trabalho e uso de si. Revista Pro-posições. Faculdade de Educação, Unicamp, n, 32, 2003.

Recebido em 03/08/2021

Aprovado em 16/09/2021

Publicado em 29/10/2021 